\title{
Herpes simplex virus and atopy in Finnish and Russian Karelian children
}

\section{To the Editors:}

Although the focus in the context of the hygiene hypothesis in explaining raised atopy prevalences has largely shifted from pathogens to commensals and saprophytes, the role of pathogens cannot be wholly ignored. Many pathogens are able to establish persistent or chronic infections, and have evolved strategies for immune evasion. A common immune subversion strategy used by such pathogens involves the increased production of the regulatory cytokines interleukin (IL)-10 and/or transforming growth factor- $\beta$ by innate immune cells or via the generation of regulatory $\mathrm{T}$ (T-reg)-cells [1]. These cytokines, by inhibiting/downregulating the function of antigen-presenting cells and effector T-cells, appear, in turn, to be crucial for the development of tolerance against allergens.

We assessed whether seropositivities to three pathogens known to readily establish persistent/chronic infections (Helicobacter pylori, Toxoplasma gondii, herpes simplex virus (HSV)) and to hepatitis A virus (HAV; previously implicated in conferring protection against allergy) are associated with reduced risk of atopy. Schoolchildren aged 7-16 yrs were randomly recruited in Finnish $(\mathrm{n}=344$; mean age $11.3 \mathrm{yrs})$ and Russian Karelia ( $n=425$; mean age 11.5 yrs), two adjacent areas with contrasting lifestyles and high and low burden of atopic diseases, respectively. Atopy was defined as one or more positive $\left(\geqslant 0.35 \mathrm{kU} \cdot \mathrm{L}^{-1}\right)$ immunoglobulin (Ig)E results to any of the 12 common inhalant and food allergens tested [2]. Specific
IgG antibodies to the four pathogens were assessed using standard methods and cut-off points.

Overall, $49 \%$ of children in Finland were atopic, compared with $20 \%$ in Russia $(\mathrm{p}<0.001)$. Approximately $26 \%$ of the children in Russia showed antibodies to T. gondii, $76 \%$ to HSV, $66 \%$ to $H$. pylori and $12 \%$ to HAV. In Finland, seropositivity rates were considerably lower and ranged from 3\% (T. gondii) and $4 \%$ (HAV) to $7 \%$ (H. pylori), with the exception of HSV, which showed a seropositivity rate of $15 \%$. When seropositivities were stratified according to the atopy status of the children, a significantly higher rate of seropositivity to HSV was found among nonatopics in Finland but not in Russia. No other differences between atopics and nonatopics in either country were found (table 1). Multivariate regression analysis revealed that seropositivity to HSV was inversely and independently associated with atopy in Finland (odds ratio (95\% confidence interval) 0.29 (0.15-0.59)) but not in Russia (0.86 (0.50-1.48)). Neither age nor other seropositivities among children in Finland or Russia appeared to be associated with atopy (table 1).

$\mathrm{HSV}$ is interesting from the perspective of tolerance and allergy. HSV infection leads to lifelong viral latency with the potential for subsequent reactivations. T-reg cells that produce IL-10 and suppress the function of CD4+ and CD8+ effector Tcells have been shown to be generated in HSV infection in vivo [3]. HSV has a glycoprotein-rich envelope that interacts with Toll-like receptor (TLR)2, and a double-stranded DNA genome rich in guanine and cytosine motifs interacting with TLR9 [4].

TABLE 1 Immunoglobulin G seropositivity to Toxoplasma gondii, herpes simplex virus (HSV), hepatitis A virus (HAV) and Helicobacter pylori among schoolchildren in Finland and Russia

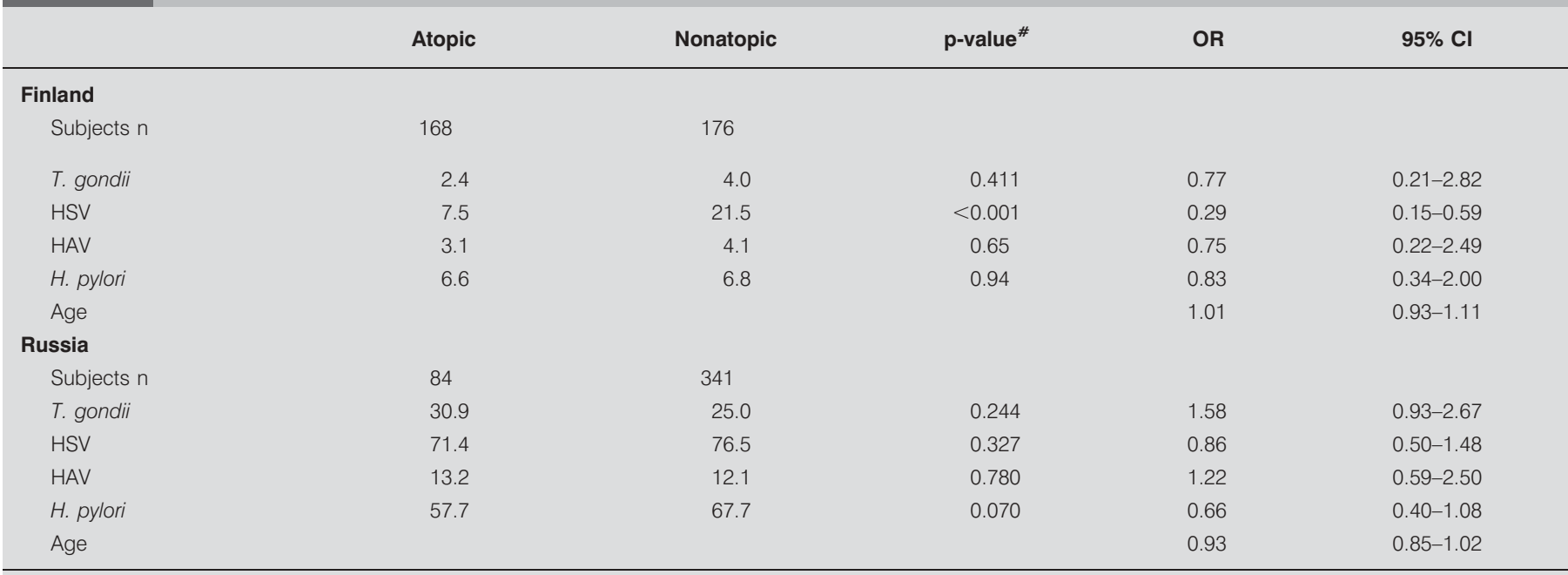

Data are presented as \%, unless otherwise stated. Data are stratified according to atopy status and associations between seropositivity and atopy derived from multiple logistic regression analysis. OR: odds ratio; Cl: confidence interval. \#: calculated using Chi-squared tests. 
Ligation of both TLR2 and 9 on human cells has been shown to be associated with the development of T-reg cells and/or tolerance $[5,6]$. We found that HSV infection conferred protection against atopy among Finnish children only. Besides the fact that atopy is infrequent in Russian Karelia, the overall exposure to microorganisms is overwhelming and the impact of saprophytes and other pathogens may well override the possible effects of HSV on the Russian side.

In summary, in an area with a relatively low microbial burden such as Finnish Karelia, herpes simplex virus appears to be able to exert immunomodulatory potential, which may have implications for the occurrence of atopy. This finding confirms the result shown previously in two other Western populations [7, 8].

L.C. von Hertzen*, P.T. Pekkarinen", T. Laatikainen", M.J. Mäkelä, and T. Haahtela for the Karelian Allergy Study Group

*Skin and Allergy Hospital, Helsinki University Central Hospital, and "Dept of Chronic Diseases and Health Promotion, National Public Health Institute, Helsinki, Finland.

\section{ACKNOWLEDGEMENTS}

The members of the Karelian Allergy Study Group also include: P. Jousilahti and E. Vartiainen (National Public Health Institute, Helsinki); and T.U. Kosunen (Helsinki University/Haartman Institute, Helsinki, Finland).

\section{SUPPORT STATEMENT}

This study was founded by a Helsinki University Central Hospital (Helsinki Finland) grant and a grant from the Allergy Foundation.

\section{STATEMENT OF INTEREST}

None declared.

\section{REFERENCES}

1 Mills KH. Regulatory T cells: friend or foe in immunity to infection?Nat Rev Immunol 2004; 4: 841-855.

2 Pekkarinen PT, von Hertzen L, Laatikainen T, et al. A disparity in the association of asthma, rhinitis, and eczema with allergen-specific $\operatorname{IgE}$ between Finnish and Russian Karelia Allergy 2007; 62: 281-287.

3 Suvas S, Azkur AK, Kim BS, Kumaraguru U, Rouse BT. CD4+CD25+ regulatory $\mathrm{T}$ cells control the severity of viral immunoinflammatory lesions J Immunol 2004; 172: 4123-4132.

4 Herbst-Kralovetz M, Pyles R. Toll-like receptors, innate immunity and HSV pathogenesis Herpes 2006; 13: 37-41.

5 Taylor RC, Richmond P, Upham JW. Toll-like receptor 2 ligands inhibit Th2 responses to mite allergens J Allergy Clin Immunol 2006; 117: 1148-1154.

6 Moseman EA, Liang X, Dawson AJ, et al. Human plasmacytoid dendritic cells activated by CpG oligodeoxynucleotides induce the generation of CD4+CD25+ regulatory T cells J Immunol 2004; 173: 4433-4442.

7 Matricardi PM, Rosmini F, Panetta V, Ferrigno L, Bonini S. Hay fever and asthma in relation to markers of infection in the United States J Allergy Clin Immunol 2002; 110: 381-387.

8 Illi S, von Mutius E, Lau S, et al. Early childhood infectious diseases and the development of asthma up to school age: a birth cohort study BMJ 2001; 322: 390-395.

\section{Variation in the tumour necrosis factor gene is not associated with susceptibility to COPD}

\section{To the Editors:}

In a recent issue of the European Respiratory Journal, TANAKA et al. [1] studied polymorphisms in the tumour necrosis factor (TNF) and lymphotoxin A genes with respect to their effect on lung function of smokers, and failed to find any association with chronic obstructive pulmonary disease (COPD) phenotypes. TANAKA et al. [1] acknowledge that their work is not a true casecontrol study, but that it would be better described as an investigation of genetic contribution to disease severity. There have been several studies of variation in TNF with respect to susceptibility to COPD, although many of these have used relatively small sample sizes and are therefore underpowered, and so are likely to lead to results that cannot be replicated.

As part of a European Union collaborative project, we have studied polymorphisms within the TNF gene in a large collection of well-characterised Caucasian COPD patients $(n=1,018)$ and control subjects $(n=911)$. COPD cases and

\begin{tabular}{|c|c|c|c|}
\hline \multirow[t]{2}{*}{ TABLE 1} & \multicolumn{3}{|c|}{$\begin{array}{l}\text { Frequency of single nucleotide polymorphisms } \\
\text { (SNPS) genotyped in the tumour necrosis factor } \\
\text { gene }\end{array}$} \\
\hline & & COPD patients & Controls \\
\hline \multicolumn{2}{|c|}{ rs1799964" (T-1031C) } & 0.207 & 0.193 \\
\hline \multicolumn{2}{|c|}{ rs $1800629^{\circ}(G-308 A)$} & 0.179 & 0.178 \\
\hline \multicolumn{2}{|c|}{ rs $361525^{\circ}(G-238 A)$} & 0.055 & 0.049 \\
\hline \multicolumn{2}{|c|}{ rs1800610 (G489A) } & 0.096 & 0.096 \\
\hline \multicolumn{2}{|c|}{ rs3093662 (A851G) } & 0.084 & 0.077 \\
\hline \multicolumn{2}{|c|}{ rs1800628 (G3512A) } & 0.127 & 0.119 \\
\hline
\end{tabular}

